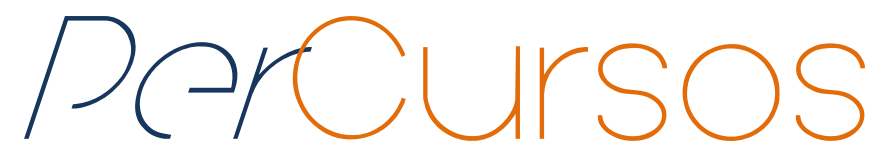

\title{
Política territorial e pobreza: o microcrédito orientado no território Oeste Catarinense
}

\begin{abstract}
Resumo
É recente a discussão que a academia, o poder público e a sociedade civil vêm realizando para diferenciar o paradigma tradicional das políticas públicas daquelas voltadas para o chamado desenvolvimento rural. E o crédito é um dos elementos estruturantes. Busca-se, neste artigo, questionar quais os principais fatores que limitaram o desenvolvimento do Microcrédito Orientado no Território Oeste Catarinense como política de atendimento aos segmentos mais vulneráveis da agricultura familiar no meio rural. $O$ estudo se caracteriza como qualitativo de cunho documental, por privilegiar a observação vivenciada e a análise dos principais documentos orientadores da política territorial. Estruturou-se o trabalho em quatro sessões, a saber: a Política Social e a pobreza rural no Brasil; a Política Territorial e sua implementação no Território Oeste Catarinense; a Política de Microcrédito Orientado e, por fim, as considerações finais. Os dados apontam: os juros altos do crédito contribuíram para limitar o acesso pelo público-alvo; baixa rentabilidade da operação para a instituição financeira; limitação ou inexistência de divulgação do programa; e uma falta de integração do Plano de Microcrédito com ações de outras políticas afins.
\end{abstract}

Palavras-chave: Desenvolvimento rural. Território nacional. Comunidades agrícolas. Financiamento agrícola. Pobreza rural - Brasil.

\author{
Carlos Eduardo Arns \\ Mestre em Desenvolvimento \\ Regional pela Universidade de \\ Santa Cruz do Sul - UNISC. \\ Doutorando em Políticas Sociais \\ e Direitos Humanos da Univ. \\ Católica de Pelotas - UCPel. \\ Brasil \\ tche@unochapeco.edu.br
}

\author{
Juliano Vitória Domingues \\ Mestre em Educação pela \\ Universidade Comunitária da \\ Região de Chapecó - \\ UNOCHAPECÓ. Professor \\ Colaborador da Univ. do Estado \\ de Santa Catarina - UDESC. \\ Brasil \\ juliano.domingues@udesc.br
}

\footnotetext{
Para citar este artigo:

ARNS, Carlos Eduardo; DOMINGUES, Juliano Vitória. Política territorial e pobreza: o microcrédito orientado no território Oeste Catarinense. Revista PerCursos, Florianópolis, v. 20, n.43, p. 91 - 119, maio/ago. 2019.
}

DOI: $10.5965 / 1984724620432019091$

http://dx.doi.org/10.5965/1984724620432019091 


\title{
Territorial policy and poverty: the oriented microcredit in the western territory of Santa Catarina/SC - Brazil
}

\begin{abstract}
There is a recent discussion that the academy, the governmental power and the civil society have been participating in, trying to differentiate themselves from the traditional paradigm of public policies aimed at the so-called rural development. And credit is one of its structuring elements. In this article, we seek to question the main factors that have limited the development of Oriented Microcredit in the Western Territory of Santa Catarina/SC - Brazil, as a policy to serve the most vulnerable segments of family agriculture in rural areas. The study is characterized as a documentary, a qualitative one, since it favours the experienced observation and the analysis of the main documents of the territorial policy. The work was structured in four sessions, which are: Social Policy and rural poverty in Brazil; the Territorial Policy and its implementation in the Western Territory of Santa Catarina; the Oriented Microcredit Policy; and finally, the final considerations. The data point to high interest rates contributed to limiting the access by the target public; low profitability of the operation for the financial institution; limited disclosure; and that there is a lack of integration of the Plane of Microcredit with actions from other related policies.
\end{abstract}

Keywords: Rural Development. National territory. Agricultural communities. Agricultural financing. Rural poverty - Brazil. 


\section{Introdução}

Desde as duas últimas décadas do século XX até o início deste novo século, o Brasil vem se defrontando com estudos e debates acadêmicos, com novos conflitos sociais e seus atores, bem como com um novo conjunto de ações do Estado que buscam se diferenciar do paradigma tradicional das políticas públicas do chamado desenvolvimento rural.

É nesse contexto que se inserem o Programa Nacional de Fortalecimento da Agricultura Familiar (PRONAF), o Programa Nacional de Apoio Territorial (PRONAT) e, mais especificamente, a política do Microcrédito Orientado no Território Oeste Catarinense (TOC), objeto da presente reflexão.

Dentre os temas discutidos na implementação da política de microcrédito, buscouse identificar neste trabalho quais os principais fatores que limitaram o desenvolvimento do Microcrédito Orientado no Território Oeste Catarinense como política de atendimento aos segmentos mais vulneráveis da agricultura familiar no meio rural. Assim, busca-se analisar as limitações desta política pública como estratégia de superação da pobreza na abordagem territorial de desenvolvimento rural no Território.

O presente estudo parte do conjunto de dados levantados e sistematizados pelos Agentes Territoriais de Inclusão Produtiva (ATIP), constituído pelos autores durante o período de 2014-2016. O estudo se caracteriza como qualitativo de cunho documental, por privilegiar a observação vivenciada e a análise dos principais documentos orientadores da política territorial. O método de coleta de informações sobre a linha de crédito do microcrédito orientado teve base no instrumento denominado de Roteiro para Obtenção de Informações sobre Microcrédito, fornecido pela extinta Secretaria do Desenvolvimento Territorial do então Ministério do Desenvolvimento Agrário (SDT/MDA).

O levantamento dos dados sobre a política pelos ATIPs foi organizado em dois momentos. O primeiro, constituído pelo levantamento de informações em documentos e materiais de experiências sobre o microcrédito. O segundo foi constituído pelo levantamento de informações primárias, com busca de informações por meio de entrevistas individuais junto aos principais agentes de crédito do território. 
O roteiro de coleta das informações se encontrava estruturado em quatro eixos: a) a situação atual da política no território, b) situação do acesso ao microcrédito, c) resultados e/ou impactos gerados pelo acesso, e d) microcrédito e integração de políticas públicas no território. Com base nessa estrutura foi montado um questionário para avaliar o microcrédito orientado no território, para gerar informações ao colegiado territorial e ao MDA, buscando equacionar os entraves da política pública no Território.

As entrevistas foram realizadas em abril de 2015 com as agências financiadoras, sendo identificados dois tipos de agências de crédito: tradicional e alternativas. As agências como modelo de crédito alternativo foram as seguintes: Cooperativa de Crédito com Interação Solidária (Cresol), a Associação Banco do Povo Crédito Solidário (uma Organização da Sociedade Civil de Interesse Público), o Banco Cooperativo Sicredi-SA (Sicredi), ao passo que o Banco do Brasil foi identificado como agência tradicional.

Após as entrevistas, a transcrição e sistematização das informações, foi realizada a análise e elaborada uma síntese. A partir da síntese, a equipe do Núcleo de Estudos de Desenvolvimento Territorial (NEDET) preparou um conjunto de reflexões que aconteceriam em eventos chamados de "Mesa de Diálogo". Nesses eventos, reuniriam-se os principais sujeitos envolvidos com a política (instituições financeiras, gestores públicos e as organizações representativas dos beneficiários), buscando mediar a construção de ações ou soluções para a melhoria da política de Microcrédito Orientado no TOC.

Assim, este texto está organizado em quatro sessões, a saber: Política Social e a pobreza rural no Brasil, em que se ressaltam as contradições da política social em regime capitalista como instrumento de enfrentamento da pobreza rural como um problema estrutural, histórico e socialmente construído; Política Territorial e sua implementação no Território Oeste Catarinense, que busca caracterizar a política territorial, demonstrar seus propósitos no enfrentamento da pobreza rural e seu processo de implementação no TOC; Política de Microcrédito Orientado no Território Oeste Catarinense, em que se trata de caracterizar a política de crédito, seus objetivos e seu papel no atendimento às famílias mais vulneráveis do meio rural e seu desenvolvimento no TOC; por fim, nas Considerações finais se busca apresentar alguns dos principais fatores limitadores da articulação entre o Microcrédito Orientado e Política Territorial, no oeste de Santa Catarina, bem como um 
conjunto de questões problematizadoras que a equipe técnica vinha formulando para o debate, com o qual o presente estudo pode contribuir para as reflexões que os atores deste e de outros territórios ainda podem e devem realizar sobre a política de microcrédito.

\section{Política social e a pobreza rural no Brasil}

Nesta seção traz-se à tona a importância da relação das políticas sociais na estratégia de superação da pobreza no país e busca-se mostrar algumas das principais contradições em contexto de regime capitalista.

No âmbito das Ciências Sociais, a política social é entendida de modo genérico como uma modalidade de política pública: ação de governo com objetivos específicos. Vianna explica que a não qualificação adequada do governo e dos objetivos específicos podem se constituir em duas armadilhas. Assim, "mais do que conferir rigor absoluto ao conceito de política pública, é importante considerar o caráter político e, portanto, circunstancial, o que equivale a dizer historicamente inteligível” (VIANNA, 2002, p. 01).

É nessa perspectiva que se busca direcionar esforços em revelar o possível caráter político e circunstancial do Microcrédito Orientado e da Política Territorial em análise.

\section{Política social}

O desempenho das políticas sociais e sua relação com a pobreza no Brasil passam pela compreensão das políticas públicas e seu papel em regimes de economias capitalistas. Nesse sentido, Pereira enfatiza que:

A integração orgânica do Brasil ao modus operandi do capitalismo, em sua fase atual, caracterizada pela promoção do capital portador de juros ao leme, é meta primeira do espúrio governo que tomou o poder político brasileiro de assalto num orquestrado golpe de Estado que culminou com a cassação do mandato da presidenta Dilma Rousseff em 2016. (Pereira, 2017, p. 24) 
Para Berhing (2011, p. 9), as expressões da questão social "encontram-se exponenciadas nesse tempo histórico de crise do capitalismo, com seus fortes impactos sobre o mundo do trabalho". Isso vem promovendo um redimensionamento da política social em todas as suas dimensões. Imprime uma dinâmica focalista e assistencialista que difere de uma visão de assistência social como política de seguridade e emancipatória. Mesmo assim, a academia convencionou que política social é "ação governamental com objetivos específicos relacionados com a proteção social” (VIANNA, 2002, p. 02).

Todavia, a proteção social, no Brasil, de viés capitalista, de histórico residual e subserviente aos ditames das elites, perde seu potencial benéfico e, "em tempos sem brios, os primeiros assaltos são contra os mais debilitados, os segmentos invisibilizados e sem poder de vocalização de suas demandas sociais" (PEREIRA, 2017, p. 28).

Para Pereira (2017), o trabalho como esforço humano foi capturado pelo modo de produção capitalista e ressignificado à sua imagem e semelhança. Assim, carrega em si a ilusão de um potencial que não possui para emancipar aqueles que a ele cedem, para sair da pobreza e das dificuldades econômicas cotidianas, pois no perfil da miséria moderna passa a contar com trabalhadores e trabalhadoras tradicionais.

Pereira (2012) constata a conjuntura mundial e brasileira da política social como sombria, mesmo diante do discurso de um novo desenvolvimentismo no rastro da elevação do país à condição de emergente. Para a autora, prevalecem tendências como: a direitização, a monetarização, a laborização precária, a descentralização da política social, com recorrente marginalização da participação social. Segundo ela, "A grande novidade tem sido a ativação compulsória dos demandantes dessa proteção para o trabalho, mediante a combinação de objetividade programática com simplicidade administrativa e baixo nível de investimento educacional" (PEREIRA, 2012, p. 750, grifo do autor).

Assim, a correlação de forças estabelecida no processo de construção do pacto social materializado na Constituição Federal de 1988 passa a encontrar um ambiente, ainda que de fortalecimento da democracia representativa (liberal), fortemente refratário à construção de políticas sociais estruturantes nos governos neoliberais (Collor/ltamarFHC) que a sucederam. Apenas nos governos progressistas do período Lula-Dilma, foram 
constituídas condições mais favoráveis, que permitiram o surgimento de algumas inovações no campo das políticas sociais, que convergiam para o espírito da Constituição Federal e voltadas às grandes demandas sociais reprimidas, como a fome, pobreza, desigualdades regionais, dentre outras.

\section{Pobreza rural}

A exclusão social e a pobreza, para Wanderlei (2017), de um ponto de vista geral, expressam a forma como o capitalismo incorpora de modo profundamente negativo as classes sociais e grupos subalternos à sua lógica de reprodução. Em sentido inverso, Martins (1997) as caracteriza como inclusão precária, ou marginal, pois na contemporaneidade, a inclusão pelo trabalho, especialmente o trabalho assalariado, vem em descenso. Para o autor, o capitalismo produz o que chama de população sobrante, aquela que tem poucas chances de reinclusão, pois o período de passagem da inclusão está deixando de ser transitório para se tornar um modo de vida.

Portanto, na agropecuária, a população assalariada se constitui em uma pequena parcela da população economicamente ativa, com perspectivas cada vez mais incertas:

As políticas de tipo desenvolvimentistas predominantes para a agropecuária brasileira estimulam a violência, atribuindo-lhe, por vezes, sentido de crueldade para a maioria que pertence às categorias subordinadas, com a agressão exterminadora contra os indígenas, os tratamentos violentos infligidos aos escravos afros e prolongados no destrato aos quilombolas, olvidados legal e socialmente das políticas públicas. (GEHLEN, 2004, p. 18)

Para Wanderley (2017), a pobreza que permanece no Brasil, tanto no campo quanto em áreas urbanas, não pode ser entendida como aquela que não foi atingida pelos processos de desenvolvimento. Ao contrário, ela é, fundamentalmente, uma pobreza gerada como consequência direta do modelo de desenvolvimento prevalecente na sociedade brasileira, cuja base é a histórica associação entre o capital, a propriedade da terra e a modernização de enfoque setorial. Foi esse meio que historicamente produziu a dissolução das muitas formas de agricultura camponesa. Por agricultura 
camponesa entende-se a categoria socioeconômica caracterizada por serem proprietários e empresários da terra e nesse trabalho constituem seus vínculos familiares. Sua dissolução vem formando proletários rurais, perdendo algumas de suas características originárias, seja a propriedade da terra, seu emprego ou a família (VELHO, 2009).

Um estudo da FAO/INCRA (GUANZIROLI; CARDIN, 2000) estimou a existência de sete milhões de estabelecimento rurais no país, na primeira metade da década de 1990, e os dividiu em quatro categorias: 1- Patronal, constituído por 500 mil estabelecimentos rurais (7,1\% do total); 2- Familiar consolidado, abarcando 1,5 milhão de estabelecimentos (21,5\%); 3- Em transição, abrangendo a 2,5 milhões de estabelecimento rurais (35,7\%); 4Periféricos, somando outros 2,5 milhões de estabelecimento rurais (35,7\%). Evidencia-se um significativo conjunto de famílias de agricultores(as) que constitui a massa de excluídos, que necessitam de políticas sociais adequadas às suas demandas e realidades especificas.

Portanto, a partir de um novo olhar sobre o rural complexificado, pretende-se resgatar um cidadão crescentemente participativo em diversas dimensões de sua existência, da qual emergem claramente dois aspectos, conforme entendimento de Gehlen (2004, p.95): "as tendências que apontam para transformações profundas do rural; e o dinamismo social expresso nas lutas por interesses específicos e pela construção de novas referências, junto e para sociedade local, nacional e mesmo global”.

\section{Política territorial e o território Oeste Catarinense}

No Brasil, os principais formuladores de políticas e as principais organizações de desenvolvimento e de operação de políticas territoriais foram as seguintes: o Ministério do Desenvolvimento Social e Combate à Fome (MDS), através dos Consórcios de Segurança Alimentar e Desenvolvimento Local (CONSAD); o Ministério do Meio Ambiente (MMA), através da Diretoria de Gestão Ambiental e Territorial; o Ministério do Trabalho e Emprego (MTE), através da Secretaria Nacional de Economia Solidária (SENAES); o Ministério da Integração Nacional (MIN), através da Secretaria de Programas Regionais e, 
por fim, o Ministério do Desenvolvimento Agrário (MDA), através da Secretaria de Desenvolvimento Territorial. Mais recentemente, em 2008, o Governo Federal criou o Programa Territórios da Cidadania, dentro da estratégia de territorialização de políticas públicas, coordenado diretamente pelo gabinete da Presidência da República.

\section{Política territorial no Brasil}

As políticas públicas de abordagem territorial podem ser consideradas recentes. Este tipo de política pública pode ser divido em duas fases distintas, considerando o período de seu surgimento mais estruturado em meados de 1990 até o ano de 2016.

De acordo com Rover (2006), em realidades rurais predominaram, no período de 1995 a 2002, as ações de abrangência municipal, especialmente através de Programas como o PRONAF, Infraestrutura e Serviços Municipais e o Comunidade Solidária, este com a abordagem do Desenvolvimento Local Integrado e Sustentável. Enquanto no período de 2003 a 2016, prevaleceu a abrangência regional na abordagem territorial das políticas.

Entre os núcleos fundamentais e o mais atuante na política territorial está a SDT que, juntamente com a Secretaria da Agricultura Familiar (SAF) e a Secretaria de Reordenamento Agrário (SRA), constituía em 2004 o também recém-criado MDA. A SDT tinha como missão "apoiar a organização e o fortalecimento institucional dos atores sociais locais na gestão participativa do desenvolvimento sustentável dos territórios rurais e promover a implementação e integração de políticas públicas” (BRASIL, 2005a).

No processo de concepção, foi adotado o conceito de território como sendo:

[...] um espaço físico, geograficamente definido, geralmente contínuo, compreendendo a cidade e o campo, caracterizado por critérios multidimensionais - tais como o ambiente, a economia, a sociedade, a cultura, a política e as instituições - e uma população com grupos sociais relativamente distintos, que se relacionam interna e externamente por meio de processos específicos, onde se pode distinguir um ou mais elementos que indicam identidade e coesão social, cultural e territorial. (BRASIL, 2005b. p. 28) 
Por meio dessa definição, os territórios rurais se caracterizam por apresentar explícita ou implicitamente a predominância dos elementos rurais em cada dimensão, como elementos marcantes da construção de sua coesão social e territorial, envolvendo inclusive os espaços urbanos de pequenas e médias cidades (BRASIL, 2005b).

Para Wanderley (2017), a adoção em 2003 pelo MDA da abordagem territorial nas políticas públicas para o atendimento das populações do campo foi um salto qualitativo em relação às políticas anteriores, precisamente pelo foco central na pobreza e desigualdade. A autora destaca que essa política buscou superar a visão dos agricultores pobres como "periféricos" para torná-los sujeitos ativos do desenvolvimento. Trata-se de uma visão integradora com a qual se pretende alcançar: a geração de riquezas com equidade, o respeito à diversidade, a solidariedade, a justiça social e a inclusão social.

Para Gehlen (2004, p. 98), a noção de agricultura familiar, "a partir das lutas sociais de resistência, reivindicações ou de produção de políticas para o setor, que se desenvolveu um conceito positivo da atividade rural, expressa pela autoestima crescente pela afirmação social", vem se consolidando como um conceito definitivo.

O espaço de gestão da Política Nacional de Apoio aos Territórios Rurais de Identidade passou a ser o Conselho Nacional de Desenvolvimento Rural e Agricultura Familiar (CONDRAF) e seus congêneres nos Estados e municípios como instâncias máximas de discussão, construção e deliberação, formando gestores públicos e representantes dos diversos segmentos do campo.

Outro componente da Política Nacional foram as Conferências (Municipais; Regionais/Territoriais; Estaduais e a Nacional) realizadas periodicamente como os espaços participativos de avaliação e construção das diretrizes da política pública.

A política era constituída de dois programas. O PROInf - Programa de Financiamento da Infraestrutura Territorial, que por editais públicos financiava projetos elaborados pelos atores locais. Outro instrumento da Política Territorial foi o PRONAT Programa Nacional de Apoio Territorial, que aportava as demais condições de funcionamento da política nacional: formação, assessorias técnicas, insumos e meios. 
Após definido um Território, aprovado o aceite e sua solicitação de adesão à política nacional, iniciava-se um conjunto de ações com equipes de assessoria técnica de entidades executoras parceiras da SDT/MDA na execução da política territorial.

\section{O Território Oeste Catarinense (TOC)}

O Estado de Santa Catarina possuía onze Territórios, no quadro da política da SDT, dos quais nove eram Territórios Rurais e dois Territórios da Cidadania. Quatro desses territórios estavam localizados na Mesorregião Oeste de Santa Catarina, conforme divisão do Instituto Brasileiro de Geografia e Estatística (IBGE): Meio Oeste Contestado (TMOC), Extremo Oeste (TEOC), Alto Uruguai Catarinense (TAUC) e o Território Oeste Catarinense (TOC). Essa mesorregião, com as regiões Sudoeste do Paraná e Noroeste do Rio Grande do Sul, integra a Mesorregião da Grande Fronteira do Mercosul.

O TOC, constituído em 2004 por 25 municípios, ampliou para 27 municípios em 2010. A maioria dos seus municípios pode ser classificada como essencialmente rural pois são municípios que dependem da agropecuária e estão na região mais agrícola do estado.

Dentre suas características mais marcantes, a ruralidade do Território se torna evidente, mesmo que, em 2010, sua população rural representasse apenas 23,48\%, segundo os critérios do IBGE (2010). O que não é pouco para os padrões atuais, já que o censo demográfico do IBGE contabilizou para o Brasil o índice de 15,63\% da população rural. De um lado, os dados demonstram que 17 dos 27 municípios possuíam menos de cinco mil habitantes. Por outro lado, apenas dois municípios possuem mais de 20 mil habitantes, dos quais deles, Chapecó, concentrava 55,18\% da população do Território. Com uma população de 183.561 mil habitantes e com a maior taxa de urbanização (91,61\%), Chapecó é o município polo e apresenta características típicas de áreas urbanas. Com relação ao comparativo entre a população rural e urbana, de acordo com o Censo de 2010, 16 municípios possuem a população rural superior à população urbana (IBGE, 2010). A partir do interesse do capital, e não da população, com uma forte concentração em

uma cidade polo em detrimento dos municípios menores, aparece claramente a contradição do atual modelo de desenvolvimento em que temos ganhadores e perdedores (VEIGA, 2007). 
A dinâmica econômica do TOC segue as características gerais da grande região oeste catarinense que concentra produção agropecuária e indústria de alimentos do estado de Santa Catarina, de acordo com os principais estudiosos da economia catarinense (CARIO et al., 2008; GOULART FILHO, 2002; LINS; MATTEI, 2001). No TOC, predomina na agricultura a produção de milho, soja e fumo, enquanto na pecuária, muito mais expressiva, a criação de suínos, aves e a produção de leite são majoritárias. A cadeia produtiva do leite se tornou a alternativa para a agricultura familiar com o processo seletivo provocado pelo sistema agroindustrial integrado nas atividades suinícola e avícola. No entanto, vêm se demonstrando que o mesmo fenômeno já ocorre na produção leiteira, em que a produção é crescente e o número de produtores é decrescente (ANSCHAU, 2011; TESTA et al., 2003).

Outra característica do TOC, visível no Plano Territorial de Desenvolvimento Rural Sustentável (PTDRS), é a presença de uma elevada densidade organizacional, perceptível tanto no setor público (Associações de Municípios, Agências de Desenvolvimento Regional, Consórcios e Sindicato dos Servidores Públicos Municipais), no setor privado (Associações Industriais e de Comércio, Câmaras de Diretores Lojistas, Lions, Rotary Clubes) como também na sociedade civil organizada (Movimento das Mulheres Camponesas - MMC, Movimento dos Trabalhadores Rurais Sem Terra - MST, Sindicato dos Trabalhadores da Agricultura Familiar) (ARNS et al, 2017).

O primeiro passo do processo de iniciação do território se efetivou com a constituição do Colegiado Territorial (CODETER). Foi composto por quatro representantes de cada município, sendo dois representantes do setor público, dois da sociedade civil (totalizando 104 membros) e 17 de organizações sociais regionais. Somam ao todo 121 membros, cuja tarefa primordial é realizar a gestão social do território.

O segundo passo do processo foi constituído pela construção participativa do diagnóstico territorial denominado à época de "Estudo Propositivo". O estudo buscava construir uma visão sistêmica da realidade, superando a visão analítica (fragmentada e setorial) tradicional da maioria dos diagnósticos. Produziu-se uma reflexão crítica sobre o modelo de desenvolvimento em curso e suas limitações, subsidiando assim a elaboração do Plano de Desenvolvimento Territorial (BRASIL, 2005a). 
O terceiro passo se desdobrou na elaboração participativa do Plano Territorial de Desenvolvimento Rural Sustentável (PTDRS), instrumento da gestão territorial. O Plano tem a finalidade de promover o desenvolvimento com igualdade, inclusão, segundo as diretrizes das políticas públicas do Governo Federal. No TOC, o PTDRS foi elaborado em 2004, com uma última revisão em 2010, vigente até 2019 (BRASIL, 2010).

O quarto passo do processo se constituiu na elaboração anual de projetos territoriais como instrumentos operacionalizadores do Plano Territorial. Nele, destacamse os projetos submetidos aos editais dos recursos do PROInf em que o Território aprovou, no período de 2004-2014, um total de 105 projetos no valor de $\mathrm{R} \$$ 13.001.258,22. Desses projetos apenas 49\% passaram por aprovação no CODETER, o que representou apenas $25 \%$ do valor total dos recursos (ARNS et al., 2017). Os autores apontam que a perda de legitimidade da política territorial, a redução do volume dos recursos do PRONAT, a restrição da participação de entidades não governamentais nos editais pela denominada criminalização das ONGs e, a consequente federalização no acesso e gestão dos recursos, foram os principais fatores para a não aprovação da maioria em órgão Colegiado. Ressalta-se que se constituem em recursos não reembolsáveis, tendo a exigência de uma pequena contrapartida por parte das organizações territoriais beneficiárias.

O quinto passo na condução da política territorial consiste no processo de gestão social do território para o qual estão previstas regimentalmente duas plenárias anuais. Constituíram duas instâncias internas ao CODETER, o Núcleo Dirigente (ND) e o Núcleo Técnico (NT) que, em 2015, foi substituído pelas Câmaras Técnicas (CTs). Em final de 2016 já eram cinco as CTs: CT de Agroecologia e Auto abastecimento, CT de Mulheres, CT de Comercialização e Inspeção Sanitária, CT do Leite. Outras duas CTs se encontravam em discussão: CT de Jovens e sucessão familiar e a CT de Povos e Comunidades Tradicionais, especialmente as nações Kaingang e Guarani.

O PTDRS de 2010 está estruturado em seis eixos estratégicos de desenvolvimento, articulando proposições e ações: 1) comercialização; 2) desenvolvimento de cadeias produtivas alternativas, com ênfase na cadeia produtiva do leite; 3) questões ambientais; 4) processo de organização; 5) educação no campo; 6) inclusão social (BRASIL, 2010). A 
partir do PTDRS e seus eixos estratégicos foi que o TOC, através do CODETER, definiu suas ações, projetos e programas e fez a gestão social do desenvolvimento com base em um conjunto de critérios estabelecidos e acordados (BADALOTTI et al., 2015).

Embora não seja o objeto deste estudo, cabe assinalar que a partir do fim, em 2016, do projeto de apoio territorial executado pela Universidade Federal da Fronteira Sul (UFFS), a equipe do NEDET foi desconstituída, os estudos realizados e os desdobramentos previstos ficaram estancados pois o órgão colegiado se desmobilizou completamente. Um conjunto das atividades de caráter territorial e regional será conduzido por outros espaços e institucionalidades, a exemplo da Associação de Municípios do Oeste Catarinense (AMOSC), Consórcio Intermunicipal de Desenvolvimento do Meio Ambiente (CIDEMA), a Agência de Desenvolvimento Regional Instituto Saga e a Associação dos Pequenos Agricultores do Oeste Catarinense (APACO).

\section{Política territorial: microcrédito no TOC}

Do modo tradicional, o crédito rural serviu para o fortalecimento da agricultura capitalista em detrimento das formas camponesas e alternativas de praticar a agricultura. De acordo com Mattei e Fossá (2017), a criação do PRONAF representa uma inflexão ao ser um esforço de atender as diferenças de segmentos e realidades socioambientais. Buscando atender as demandas da agricultura familiar, derivou-se do programa um conjunto de linhas de crédito de cobertura geral e outras de atendimento às especificidades de segmentos sociais. O microcrédito orientado é um desses programas.

\section{Caracterização do Microcrédito Produtivo Orientado}

O Programa de Microcrédito Produtivo Orientado (PMPO) é um importante insumo à geração de trabalho e renda e redução da pobreza, integrando o Programa Crescer, que constitui o eixo da inclusão produtiva do Plano Brasil Sem Miséria do Ministério do Desenvolvimento Social (ZIPPERER, 2015).

No meio rural, o microcrédito é uma linha de crédito criada no ano 2000 e está ligada ao PRONAF. É destinado aos agricultores de baixa renda, permitindo o 
financiamento das atividades agropecuárias e não agropecuárias, podendo os créditos cobrir qualquer demanda que possa gerar renda para a família atendida. Os créditos são destinados para acesso de agricultores familiares enquadrados no Grupo B (agricultores com baixa produção e pouco potencial de aumento, no qual também estão incluídos indígenas e quilombolas) e agricultores integrantes das unidades familiares de produção enquadradas nos Grupos A ou A/C (agricultores assentados da reforma agrária) ${ }^{1}$.

Para acessar esse crédito, a família precisa da Declaração de Aptidão ao PRONAF (DAP), uma proposta simplificada de crédito e o CPF regularizado. De acordo com as informações do Ministério, os agricultores beneficiados pelo microcrédito têm acesso a Assistência Técnica e Extensão Rural por meio dos convênios com a SAF do MDA, por instituições públicas e ONGs, com o objetivo de integrar com a Política Nacional de Assistência Técnica e Extensão Rural (Pnater) (BRASIL/MDA, 2015). Segundo o Manual de Crédito Rural (BRASIL/MCR, 2014), o limite de financiamento é de $R \$ 2.500,00$ por beneficiário ou ampliado para $\mathrm{R} \$$ 4.000,00 com a inclusão de um plano de microcrédito.

Os principais atrativos dessa linha de crédito são a taxa de juros de 0,5\% ao ano e o bônus por adimplência, com a redução do montante a ser pago de $25 \%$, podendo ser de até $40 \%$ para o semiárido, além do prazo para pagamento de até dois anos. Para concessão de crédito havia um monitoramento dessa política com duas principais exigências aos municípios: i) não atinjam 15\% de taxa de inadimplência e ii) o número de contratos inadimplentes seja menor que 50. Por isso, o MDA alertava para a concessão racional e integrada do crédito à realidade da família.

Das entrevistas realizadas, apenas uma instituição financeira, a Cresol, operava o microcrédito produtivo orientado para o meio rural no Território Oeste Catarinense. Diante dessa constatação, as informações possibilitam uma significativa aproximação da execução da política numa abordagem territorial.

\footnotetext{
${ }^{1}$ Cada uma das linhas de crédito está descrita no Manual de Crédito Rural, documento que codifica as normas de crédito. O manual é publicado pelo Banco Central do Brasil.
} 


\section{Situação do microcrédito orientado no território Oeste Catarinense}

A primeira constatação empírica feita pela equipe de assessores, já no início de sua atuação junto ao TOC, foi que o Microcrédito Orientado não vinha sendo executado ou era executado com pouca significância junto ao seu público no Território, observação confirmada pelos dados levantados e opiniões colhidas no percurso do estudo.

Diante dos dados de crédito fornecidos pela organização financeira Cresol Central SC/RS, apenas 776 agricultores familiares acessaram microcrédito no período de 2004 a 2014. Houve 1449 operações, no valor total de $\mathrm{R} \$$ 4.734.027,71. A média do valor dos contratos foi de $\mathrm{R} \$ 4.826,24$, e de 11 contratos ao ano em todo o Território. A finalidade do uso do microcrédito foi para pequenos investimentos, como aquisição de máquinas, equipamentos e capital de giro. Cada operação era dividida em sete parcelas e prazo de reembolso de 9,5 meses. Dos contratos firmados, se somados os contratos realizados por mulheres e jovens, a participação foi de $18,9 \%$ do total. Contudo, não houve operação de microcrédito para povos tradicionais, sendo que no Território existem áreas indígenas e pescadores, mas não se tem registro de áreas quilombolas. Merece referência o grupo social denominado de caboclo, identificado e caracterizado como povo tradicional em diversos trabalhos, dentre os quais destacamos Poli (1991) e Podeleski; Stropasolas (2014), Tecchio (2017), Cipriano (2017). No acesso ao crédito, não havia esta identificação.

Em 2015, a Cresol Central SC/RS possuía sete cooperativas de crédito atuando no Território Oeste Catarinense, dentre as quais a Cooperativa de Xaxim não se localiza no território, mas possuía cinco dos 14 Postos de Atendimento da Cooperativa (PAC). Desse modo, 19 dos 27 municípios do Território (70,37\%) possuíam agências de crédito ou PAC, como pode ser observado na Tabela 01.

A partir dos dados da Tabela 01 podem ser identificadas três gerações de cooperativas que correspondem a ambientes institucionais e políticos distintos. O sistema Cresol tem origem na mobilização de movimentos sociais e sindical, com apoio de ONG de desenvolvimento rural, em busca do acesso ao crédito para a agricultura familiar.

A primeira geração (1993-1995) é constituída antes do surgimento do PRONAF e seus desdobramentos, desencadeado a partir da constituição, em 1993, da cooperativa 
de crédito solidário de Quilombo/SC. Foi a primeira organização de crédito dessa natureza na região da Mesofronteira do Mercosul, a partir da qual se desencadeou um amplo processo de organização do cooperativismo de crédito. A segunda geração (1996-2002) pode ser considerada a das cooperativas de crédito que se constituem no período de vigência inicial do PRONAF. É o caso das cooperativas de Chapecó e Xaxim. A terceira geração de cooperativas de crédito (2003 em diante) se constitui na expansão promovida pelo movimento das cooperativas do sistema $\mathrm{Cresol}^{2}$, no bojo do ambiente produzido pelo conjunto das novas políticas públicas dos governos populares de Lula e Dilma.

Tabela 01 - Municípios com Cooperativas de Crédito e PAC's, ano de fundação e número de sócios da Cooperativa do Território Oeste Catarinense

\begin{tabular}{|l|l|c|l|}
\hline Agência e município & $\begin{array}{l}\text { Data } \\
\text { Fundação }\end{array}$ & $\begin{array}{l}\text { Número } \\
\text { de } \\
\text { sócios }\end{array}$ & Municípios com PAC \\
\hline Cresol Chapecó & $23 / 10 / 2000$ & 4.830 & Nova Itaberaba \\
\hline $\begin{array}{l}\text { Cresol Oeste } \\
\text { Catarinense/Xaxim }\end{array}$ & $28 / 07 / 2000$ & 6.728 & $\begin{array}{l}\text { Caxambu do Sul; Águas de Chapecó; } \\
\text { Santiago do Sul; Novo Horizonte; } \\
\text { Jardinópolis; }\end{array}$ \\
\hline Cresol Pinhalzinho & $03 / 03 / 2005$ & 3.928 & Nova Erechim; Saudades; \\
\hline Cresol Coronel Freitas & $13 / 11 / 2006$ & 1.504 & Águas Frias \\
\hline Cresol Quilombo & $03 / 06 / 1993$ & 4.250 & Irati; União do Oeste; \\
\hline Cresol Formosa & $14 / 06 / 2002$ & 3.748 & São Lourenço \\
\hline Santa Terezinha & $30 / 10 / 2006$ & 1.985 & Campo Erê \\
\hline TOTAL: 07 & - & $\mathbf{2 6 . 9 7 3}$ & 13 municípios \\
\hline
\end{tabular}

Fonte: Elaborado pelos autores, com base nos dados fornecidos por UNICAFES/SC, 2018.

A seguir, os dados apresentados na Tabela 02 mostram que os 26.973 associados das sete cooperativas representam 44,57\% e 20,27\% da população rural e da população total dos municípios do Território, respectivamente. Representam $77,47 \%$ do total da população rural e 78.092 habitantes do Território em 2010 (IBGE, 2010). A Cresol Formosa é a cooperativa que apresenta a maior relação de associados da população rural $(58,30 \%)$

\footnotetext{
${ }^{2}$ O Sistema Cresol foi constituído em 1996 a partir de cinco cooperativas singulares. Em 2016 foi fortalecido com a integração da Cresol Confederação, fortalecendo o Cooperativismo Solidário. Nesse período, o Sistema aumentou a área de abrangência contando com mais de 200 mil famílias cooperadas.
} 
em sua área de abrangência, enquanto a menor proporção da população rural associada (25,23\%) está na Cresol Chapecó. A Cresol Pinhalzinho possui o maior número de estabelecimentos rurais (5.325) na sua base territorial de atuação, pela soma dos municípios de Pinhalzinho, Nova Erechim e Saudades, enquanto a Cresol Coronel Freitas possui o menor número de estabelecimentos rurais (1.563) em sua área.

Tabela 02 - População, número de estabelecimentos rurais e número de sócios da cooperativa dos municípios de abrangência da Cooperativa e seus PACs, no Território

Oeste Catarinense

\begin{tabular}{|l|c|c|c|}
\hline Agência e Município & \multicolumn{1}{|c|}{$\begin{array}{l}\text { População }_{\text {Rural }^{2}} \\
\text { 1- Cresol Chapecó }\end{array}$} & $\begin{array}{l}\text { Estabelecimentos }_{\text {Rurais }^{2}} \\
\text { Número de Sócios }^{1}\end{array}$ \\
\hline $\begin{array}{l}\text { 2- Cresol Oeste } \\
\text { Catarinense } \\
\text { Xaxim }\end{array}$ & 8.740 & 2.556 & 4.830 \\
\hline 3- Cresol Pinhalzinho & 7.174 & 2.720 & $6.728^{4}$ \\
\hline 4- Cresol Coronel Freitas & 5.589 & 5.325 & $3.928^{5}$ \\
\hline 5- Cresol Quilombo & 7.952 & 1.563 & 1.504 \\
\hline 6- Cresol Formosa & 6.429 & 2.262 & 4.250 \\
\hline 7- Santa Terezinha & 5.475 & 1.850 & 3.748 \\
\hline TOTAL & 60.498 & $767^{6}$ & 26.973 \\
\hline
\end{tabular}

1 Dados fornecidos por e-mail pela Unicafes/SC, sede Chapecó;

2 Censo do IBGE de 2010;

3 O município de Xaxim, Sede da Cooperativa, não faz parte do Território Oeste Catarinense;

4 Não foi possível excluir os associados do município de Xaxim;

5 Estão inclusos os associados do município de Modelo, que não faz parte do TOC;

6 Não estão incluídos os estabelecimentos rurais do município de Campo Erê.

A Figura 02 apresenta o mapa do TOC com uma tipologia dos municípios por número de projetos por faixa de valor contratado nos 11 anos (2003-2014) das operações do Microcrédito Orientado nas agências da Cresol e a distribuição do crédito no território.

A partir dos dados, pode-se verificar uma significativa variação entre os municípios, com relação ao número e valores de contratos aprovados. Apresenta-se uma tipologia de quatro categorias por número de projetos aprovados por município, conforme segue: 
Tipo 1 - Municípios com mais de 10 projetos por ano: neste grupo encontram-se apenas três municípios (Chapecó, Guatambu e Coronel Freitas);

Tipo 2 - Municípios com 01 a 10 projetos por ano: envolve oito municípios (Águas Frias, Cordilheira Alta, Irati, Nova Itaberaba, Pinhalzinho, Quilombo, Saudades e Sul Brasil);

Tipo 3 - Municípios com menos de 01 projeto aprovado por ano: abrange oito municípios (Campo Êre, Formosa do Sul, Jardinópolis, Nova Erechim, Novo Horizonte, São Bernardino, São Lourenço do Oeste e União do Oeste);

Tipo 4 - Municípios sem projetos aprovados no período: neste grupo encontramse oito municípios (Caxambu do Sul, Planalto Alegre, Águas de Chapecó, São Carlos, Serra Alta, Santa Terezinha do Progresso, Saltinho, Santiago do Sul).

Figura 02 - Tipificação dos municípios por faixa de valor contratado de microcrédito no Território Oeste Catarinense

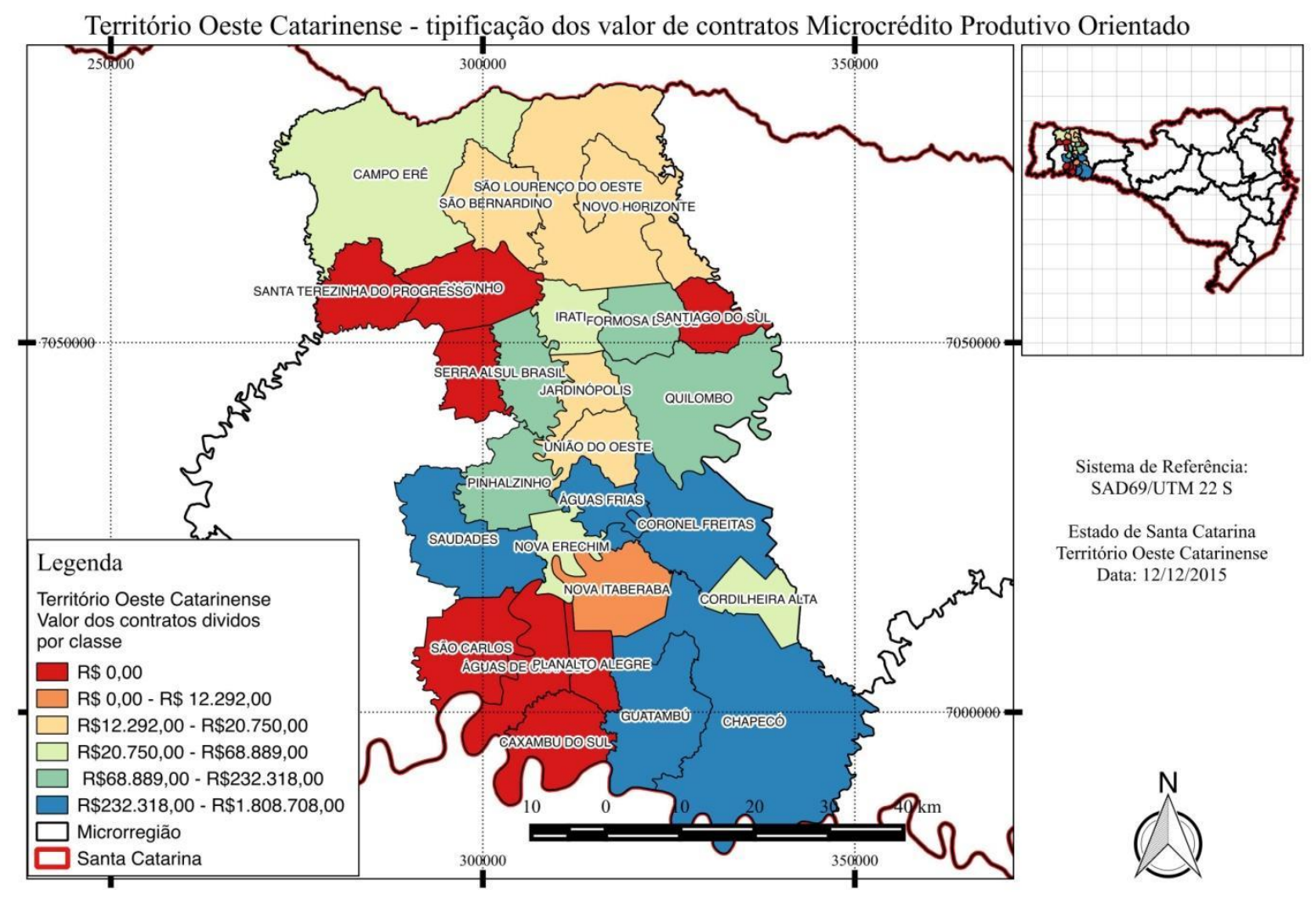

Fonte: elaborado pelos autores, 2015. 
Segundo dirigentes da Cresol, a explicação para a diferença de contratos entre os municípios se deve ao tamanho da população e à característica empreendedora dos agricultores familiares. Ou seja, na opinião dos dirigentes, esses fatores podem ser uma explicação, mas algumas contradições podem ser evidenciadas.

1- Municípios mais populosos e empreendedores: neste critério, evidentemente, se enquadra o caso de Chapecó como o município mais populoso do Território e com economia bastante dinâmica, porém não explica o fato de Pinhalzinho (Tipo 2) e São Lourenço do Oeste (Tipo 3) não constituírem a mesma categoria pois, guardadas as devidas proporções, também possuem maior população e possuem economias mais dinâmicas.

2- Finalidade de inclusão produtiva da política: trata-se de um argumento contraditório na medida em que a maioria dos municípios com maior concentração de famílias rurais pobres está enquadrada no Tipo 3 (Campo Êre, São Bernardino, Jardinópolis, União do Oeste e Formosa do Sul) e no Tipo 4 (sem) que não operaram projetos no período de 2003-2014 (Santa Terezinha do Progresso e Águas de Chapecó).

3- Entorno mais dinâmico, favorecendo o empreendedorismo: representa uma contradição, pois não explicaria o fato de os municípios de Nova Itaberaba e Cordilheira Alta não estarem inseridas no Tipo 1, juntamente com Guatambu, por serem municípios fronteiriços com Chapecó e pela proximidade e facilidade de acesso a agências de crédito.

Proporcionalmente, os municípios menores possuem uma participação relativamente maior no conjunto de famílias ou unidades produtivas aptas para acessar essa linha de crédito. Os dados e a explicação apresentada pelos agentes de crédito tendem a indicar que não houve uma busca ativa pelo público por parte do agente financeiro, aguardando a procura espontânea dos interessados. No caso das pequenas cooperativas de crédito, torna-se compreensível pela falta de estrutura para uma ação onerosa de busca ativa sem apoio de parcerias adequadas.

Percebe-se que os dados do número de contratos e, por conseguinte, do valor total desses contratos visualizados numa escala temporal, confirmam a constatação empírica inicial da equipe do NEDET referente à pouca significância e operação dessa 
política pública no Território Oeste Catarinense. O Gráfico 01 permite verificar inclusive uma redução crescente na implementação política.

Gráfico 01 - Distribuição do número e valor dos contratos operados por ano, no período de 2004-2014, no Território Oeste Catarinense

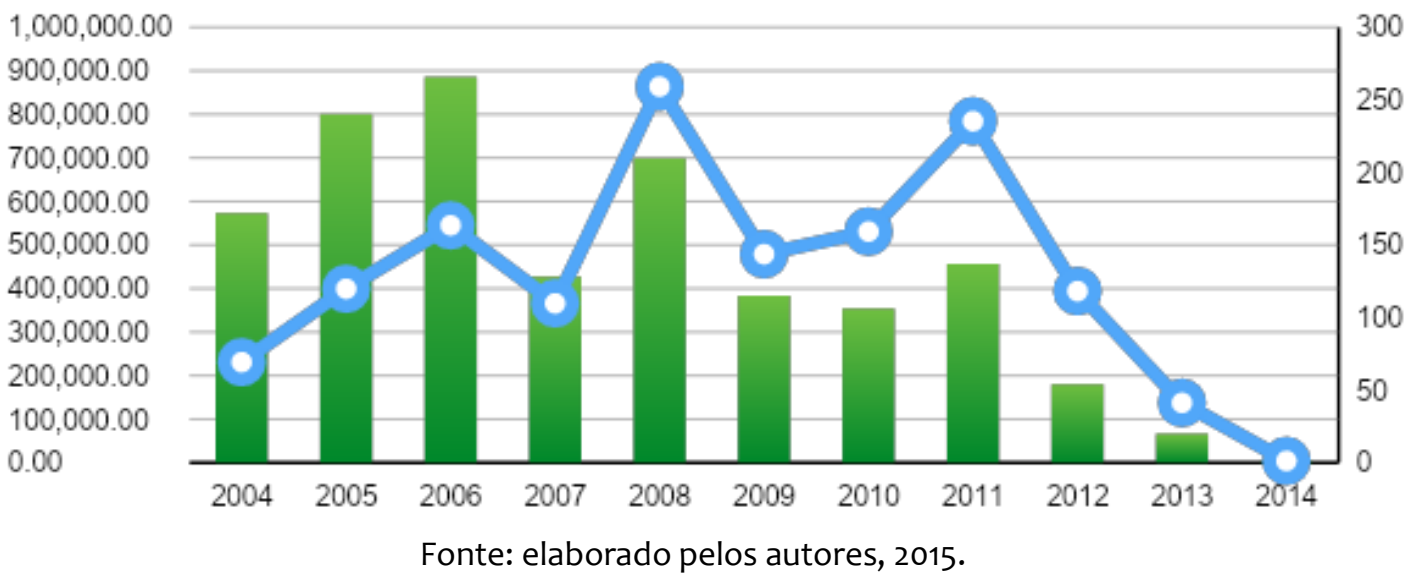

Não obstante, os dados permitem visualizar também o aumento significativo da média dos contratos anuais sem levar em conta a deflação. Se observarmos o ano de 2004, percebemos que o número de contratos era menor do que do ano de 2008, ou seja, um aumento de $22 \%$. No entanto, o valor dos contratos teve um aumento de $274 \%$, o que quer dizer que a média dos valores dos contratos teve esse aumento substancial. A partir de 2008, o número de contratos foi retraindo até chegar em apenas um contrato executado em 2014, com consequências no volume total de recursos. Percebe-se, no entanto, que o seu valor médio foi se elevando, chegando em 2012 em $R \$ 7.295,74$. Ou seja, um aumento de $443 \%$ em relação à média dos contratos realizados no primeiro ano.

A explicação para a queda da execução do microcrédito em 2008 foi que em junho desse ano o PRONAF passou a contar com taxas de juros muito baixas, em média de $2 \%$ ao ano, sendo que o microcrédito era operacionalizado a $2,25 \%$ ao mês. A diferença impactante entre taxas acontecia porque as cooperativas não tinham acesso ao subsídio do tesouro nacional, com taxas de juros de $0,5 \%$ ao ano. 
Houve uma priorização do acesso para outras linhas já que para a cooperativa que operacionalizava e para os beneficiários não era comparativamente viável. No ano de 2011, o aumento é explicado pela estiagem que ocorreu, influenciando no aumento de operações na busca por capital de giro.

\section{Situação do acesso ao microcrédito}

A agência que prestou a informação afirmou que, em 2015, as exigências para acesso ao microcrédito eram mínimas e direcionadas a um público específico. $O$ agricultor não poderia possuir restrição jurídica, ter renda de até 120 mil por ano, não somar 15 mil em operações de microcrédito por safra e, no caso da Cresol, ser sócio, além de não comprometer mais que $30 \%$ da sua renda na parcela financiada.

De acordo com o dirigente dessa agência, um fator para o pouco uso da linha de microcrédito se deve à baixa rentabilidade que essas operações proporcionam às agências e, por conseguinte, restrito estímulo para a divulgação e a busca por clientes. Tal situação leva o agricultor a ter pouca informação sobre a existência do programa e suas vantagens. Essa afirmação é confirmada pelo estudo realizado no Território Oeste Catarinense, por Zipperer (2015), segundo o qual 72\% dos microempreendedores que contrataram o microcrédito ficaram sabendo da existência do programa na agência.

O mesmo autor afirma ainda que o programa atingiu suas metas de valores e número de contratos, mas não houve o acesso esperado pelo público alvo. Ou seja, os miseráveis não acessaram o programa, conforme as metas e objetivos do Plano Brasil sem Miséria $(\mathrm{PBSM})^{3}$. Da sua amostra de 40 entrevistados, um era beneficiário do Programa Bolsa Família (PBF) ${ }^{4}$. Os demais tomadores de microcrédito atuavam na área de serviços ou comércio, possuíam ensino superior e médio, já eram microempreendedores por 10 anos e boa parte deles (38\%) possuíam renda bruta de $\mathrm{R} \$$ 5,8 mil mensal, situação muito distinta do público rural, especialmente os beneficiários do PBF.

${ }^{3}$ O Plano Brasil Sem Miséria foi lançado em 2011 pelo Governo Federal e coordenado pelo MDS. Tinha o objetivo ambicioso de superar a extrema pobreza a partir da constatação da existência de 7,6 milhões de pessoas em extrema pobreza, concentradas especialmente nas regiões Nordeste e Norte do país.

${ }^{4}$ O Programa Bolsa Família foi criado no início do governo Lula e unificou um conjunto de programas de transferência de renda para famílias pobres e extremamente pobres. A contrapartida é que essas famílias tenham seus filhos matriculados na escola, mantenham vacinação e acompanhamento da gestação, quando for o caso. $\mathrm{O}$ intuito é quebrar o ciclo geracional de pobreza nos curto e longo prazos. 
Neste estudo, duas outras questões se evidenciaram e merecem ser destacadas. A primeira é que para as cooperativas de crédito operacionalizarem o microcrédito é requisito realizar um diagnóstico da unidade de produção para conhecer os objetivos da família e seu sistema de produção; compreender a movimentação financeira anual e estrutura produtiva existente, além de outros fatores para o sucesso no uso adequado do crédito. Por um lado, se consegue caracterizar com mais clareza a capacidade de pagamento, o tipo de risco no acesso, gerando maior segurança para as agências nas operações, consistência nas orientações, bem como menor risco para o próprio tomador. Por outro lado, além de ser uma operação trabalhosa da agência, para a instituição financeira não se torna atrativo operacionalizar o microcrédito, considerando a alta taxa de juro para o público-alvo e a informada alta taxa de inadimplência no programa - o número da taxa não foi informado, foi dito apenas que era alta.

Diante do exposto, percebeu-se que não há por parte das agências uma ação proativa que fomente o microcrédito. Isso acontece pelo baixo volume de cada operação, pelo risco de inadimplência, pela baixa disponibilidade de recursos humanos para atender adequadamente a operacionalização nas instituições financeiras.

\section{Microcrédito e integração de políticas públicas no território}

O estudo possibilitou perceber que existe uma fraca integração da política do microcrédito com outras políticas públicas dentro das agências financiadoras. 0 microcrédito é tratado como mais um produto financeiro da carteira de crédito, como as demais linhas de crédito operadas e, momentaneamente, de pouca vantagem. Essa orientação está afirmada por programas como PRONAF e PRONAMP, pois sua operação é realizada na forma de prestação de serviço por repasse dos recursos.

O mesmo ocorre com os demais agentes envolvidos no processo de produção no território. Dentro dos limites deste estudo também não foi possível identificar evidência de ações integradas, especialmente junto aos municípios, entre as secretarias e órgãos estaduais com atuação local, para articular ações entre o PRONAF, Programa de Aquisição de Alimentos, Rede do Centro Nacional de Formação e Apoio à Economia Solidária, Programa Nacional de Acesso ao Ensino Técnico e Emprego, dentre outras. 
Fica evidente que o microcrédito não se integrou à política territorial pois em nenhum documento foi identificado relato de discussão sobre crédito realizado no Colegiado Territorial. No período de atuação do NEDET não se obteve informação sobre nenhuma ação que tivesse discutido o crédito no Território Oeste Catarinense.

Para as cooperativas de crédito, isso pode estar associado à falta de estrutura material e humana, enquanto para os demais agentes, permanece a suspeita maior sobre o fato de o microcrédito não ser atrativo financeiramente. Isso é expresso pelo baixo spread ${ }^{5}$ para um e, para outro, expresso por uma provável inadimplência.

De acordo com as instituições entrevistadas, uma saída seria a criação de um fundo de aval estadual ou fundo garantidor estadual, que possa dar lastro às operações financeiras realizadas. Além disso, apontam que é necessário um processo programado de acompanhamento sistemático dos agricultores e suas unidades produtivas para além das visitas previstas pelo Programa Nacional de Microcrédito Produtivo e Orientado.

\section{Considerações finais}

Os dados levantados pelas entrevistas com funcionários de agências de cooperativas de crédito e análise realizada apontam um conjunto de problemas, que podem ser sintetizados nos seguintes pontos:

1. Os juros altos do PNMPO operado no território comparado ao PRONAF contribuíram para limitar o acesso pelo público-alvo;

2. Baixa rentabilidade da operação para a instituição financeira e a informada alta taxa de inadimplência comparativa do programa desestimularam os agentes financeiros na implementação da linha de crédito;

3. O desinteresse das agências financeiras contribuiu para a limitada divulgação do programa, gerando desconhecimento desse crédito pelos agricultores familiares;

\footnotetext{
${ }^{5}$ Spread significa a diferença entre taxas de juros de aplicação e de captação, compreendendo o lucro e o risco relativos às operações de crédito (BRASIL, 2015).
} 
4. A integração do PNMPO com ações de outras políticas afins aconteceu de modo pouco evidente como, por exemplo, a assistência técnica propiciou a falta de orientação após o crédito contratado e pode ter favorecido a inadimplência;

5. A falta de acesso a programas de crédito com condições mais adequadas de pagamento e subsídios (Ex.: Programa Crescer Microcrédito) dificultou às cooperativas de crédito apresentar produtos mais adequados para as condições presentes entre seu quadro associativo e a constituição de uma estrutura mais adequada e viável, técnica e economicamente, para apoio aos tomadores de crédito.

Outro elemento evidenciado é a falta de integração e articulação das políticas públicas voltadas às populações mais pobres, como a formação, a assistência técnica, o acesso ao mercado. No entanto, isso contraria as proposições contidas nos documentos de referência pois, conforme Wanderley (2017) e Cazella et al. (2016), a política territorial se propunha a associar o crédito rural a outras políticas públicas de suporte que procuram apreender melhor a complexidade da situação dos agricultores mais pobres.

Os dados revelaram também que, no caso do Microcrédito Orientado no TOC, não foi alcançado de forma consistente o público prioritário (os mais pobres do campo), ou seja, os indígenas, os pescadores artesanais, nem os camponeses mais pobres e descapitalizados do território. São esses os sujeitos para os quais o programa foi desenhado, conforme observou Rocha (2011).

Os problemas apontados na política de Microcrédito Produtivo Orientado revelam também vários elementos de incoerência da proposta com a realidade/público a que se destina, como também detectaram Cazella et al. (2016) na análise realizada para o PRONAF e outras políticas públicas voltadas ao campo.

A partir do estudo e seus resultados alcançados, a equipe técnica do NEDET organizou uma atividade reflexiva junto ao CODETER para que, junto às organizações financiadoras, se fizesse a negociação. Para tanto, a equipe do NEDET formulou um conjunto de questões orientadoras das discussões, conforme segue:

- No que tange à finalidade e ao público-alvo do programa, identifica-se uma preferência ao acesso dos recursos do PRONAF ao invés do microcrédito: será que o 
microcrédito produtivo orientado e o PRONAF não estão cumprindo com a mesma função e atingindo uma mesma faixa de público no Território?

- Percebe-se que o PNMPO está sendo mais procurado por tomadores de perfil mais empreendedor e localizado em realidades economicamente mais dinâmicas: será que este programa está atendendo realmente ao público-alvo, caracterizado como carente, ou miseráveis, do Território ou investindo em microempreendedores já incluídos em sistemas produtivos?

- Foi observada a falta de integração do MPO com outras políticas públicas (Ater, PNAE, Cooperativismo, dentre outros): em que o CODETER poderia contribuir para garantir maior integração e efetividade das políticas de inclusão produtiva no TOC?

\section{REFERÊNCIAS}

ANSCHAU, Cleusa T. Redes cooperativas da bovinocultura de leite e o desenvolvimento do Oeste catarinense. 2011. Dissertação (Mestrado em Ciências Ambientais) - Programa de Pós-Graduação em Ciências Ambientais, UNOCHAPECÓ. Chapecó, 2011.

ARNS, Carlos Eduardo et al. A trajetória do Proinf na construção da política territorial no território Oeste catarinense. In: CONGRESSO DA SOCIEDADE DE ECONOMIA, ADMINISTRAÇÃO E SOCIOLOGIA RURAL, 55., 2017, Santa Maria. Anais [...]. Santa Maria, RS: UFSM, 2017. Tema: Inovação, extensão e cooperação para o desenvolvimento.

BADALOTTI, Rosana Maria et al. Possibilidades e limites das ações de implementadas no território Oeste para o desenvolvimento rural. P. 1-22. In: SEMINÁRIO INTERNACIONAL DE DESENVOLVIMENTO REGIONAL, 7., 2015, Santa Cruz do Sul. Anais [...]. Santa Cruz do Sul, RS: UNISC, 2015. Tema: Globalização em tempos de regionalização: repercussões no território.

BERHING, Elaine Rossetti. Desafios contemporâneos das políticas sociais. Revista Katálysis, Florianópolis, v. 14, n. 1, p. 09-10, jan./jun. 2011.

BRASIL. Banco Central do Brasil. MCR: manual de crédito rural: microcrédito produtivo orientado. 2014/2015. Brasília: Banco Central do Brasil, 2014. Disponível em:

https://www3.bcb.gov.br/mcr. Acesso em: 12 jun. 2015. 
BRASIL. Ministério do Desenvolvimento Agrário. Crédito rural: linhas de crédito. Brasília: MDA, 2015. Disponível em: http://www.mda.gov.br/sitemda/secretaria/safcreditorural/sobre-o-programa. Acesso em: 12 jun. 2015.

. Plano territorial de desenvolvimento rural sustentável: território Oeste catarinense. Florianópolis: SDT/MDA, 2010.

. Marco referência para apoio ao desenvolvimento territorial. Brasília: SDT/MDA, 2005a. (Série Documentos Institucionais. 02-2005.)

. Referências para uma estratégia de desenvolvimento rural sustentável no Brasil. Brasília: SDT/MDA, 2005b. (Série Documentos número 01.)

CARIO, Silvio Antonio Ferraz et al. (orgs.). Economia de Santa Catarina: inserção industrial e dinâmica competitiva. Blumenau: Nova Letra, 2008.

CAZELLA, Ademir Antonio et. al. Políticas públicas de desenvolvimento rural no Brasil: o dilema entre inclusão produtiva e assistência social. Política \& Sociedade, Florianópolis, v. 15, ed. especial, p. 49-79, 2016.

CIPRIANO, Luís Olimpio Stalchmidt. Comunidades rurais caboclas no território Meio Oeste Contestado - SC. 2017. Dissertação (Mestrado em Agroecossistemas) - Programa de Pós-Graduação em Agroecossistemas, UFSC. Florianópolis, 2017.

GEHLEN, Ivaldo. Políticas públicas e desenvolvimento social rural. São Paulo em Perspectiva, São Paulo, v. 18, n. 2, p. 95-103, jun. 2004.

GOULART FILHO, Alcides. A formação econômica de Santa Catarina. Ensaios FEE, Porto Alegre, v. 23, n. 2, p. 977-1007, 2002.

GUANZIROLI, Carlos Enrique; CARDIM, Silvia Elizabeth de C. S. (coords.). Novo retrato da agricultura familiar: o Brasil redescoberto. Brasília: MDA, 2000.

IBGE. Instituto Brasileiro de Geografia e Estatística. Censo demográfico. Brasília, DF: IBGE, 2010. Disponível em: ibge.gov.br. Acesso em: 22 ago. 2018.

LINS, Hoyêdo Nunes, MATTEI, Lauro. A socioeconomia catarinense no limiar do Século XXI. In: CARIO, Silvio Antonio Ferraz; PEREIRA, Laércio Barbosa; KOEHLER, Márcio (orgs.). Padrão produtivo e dinâmica econômica competitiva: estudos sobre setores selecionados em Santa Catarina. Florianópolis: EDUFSC, 2001.

MARTINS, José de Souza. 1997. Exclusão social e a nova desigualdade. 2 ed. São Paulo: Paulus, 1997. 
MATTEI, Lauro Francisco; FOSSÁ, Juliano Luiz. A evolução do crédito rural no Estado de Santa Catarina entre 2007 e 2016. Revista Grifos, Chapecó, n.43, p. 65-82, 2017.

PEREIRA, Camila Potyara. A proteção social em tempos sem brios. Revista Argumentum, Vitória, v. 9, n. 3, p. 24-29, set./dez. 2017.

PEREIRA, Potyara Amazoneida Pereira. Utopias desenvolvimentistas e política social no Brasil. Ser. Soc. Soc., São Paulo, n.112, p. 729-753, out./dez. 2012.

PODELESKI, Onete da Silva; STROPASOLAS, Valmir Luiz. Remanescentes do contestado em Taquaruçu: da invisibilização histórica ao reconhecimento social como sujeitos de direitos. INTERthesis, Florianópolis, v. 11, n. 2, jul./dez. 2014.

POLI, Jaci. Caboclo: pioneirismo e marginalização. Cadernos do CEOM, Chapecó, ano 5, n. 7, abr. 1991.

ROCHA, Sonia. O programa Bolsa Família: evolução e efeitos sobre a pobreza. Economia e Sociedade, Campinas, v. 20, n. 1, p. 113-139, abr. 2011.

ROVER, Oscar José. Desenvolvimento local em territórios rurais: análise de políticas federais do período de 1994-2005. P. 2-30. In: ENCONTRO ANUAL DA ANPOCS, 30., 2006, Caxambu. Anais [...]. Caxambu: [s.n.], 2006.

TECCHIO, Andréia. Pobreza e territorialização da ação pública no território Meio Oeste Contestado (SC). 2017. Tese (Doutorado em Ciências Sociais) - Programa de Pósgraduação de Ciências Sociais em Desenvolvimento, Agricultura e Sociedade, UFRJ. Rio de Janeiro, 2017.

TESTA, Vilson Marcos et al. A escolha da trajetória da produção de leite como estratégia de desenvolvimento do Oeste Catarinense. Florianópolis, SC: Epagri, 2003.

VEIGA, José Eli da. Mudanças nas relações entre espaços rurais e urbanos. G\&DR, Taubaté, v. 3, n. 1, p. 123-149, jan./abr. 2007.

VELHO, Otávio Guilherme A. C. O conceito de camponês e sua aplicação à análise do meio rural brasileiro. In: WELCH, Clifford Andrew (org.) Camponeses brasileiros: leituras e interpretações clássicas, v. 1. São Paulo, SP: Editora UNESP; Brasília, DF: Núcleo de Estudos Agrários e Desenvolvimento Rural, 2009.

VIANNA, Maria Lucia Teixeira Werneck. Em torno do conceito de política social: notas introdutórias. Rio de Janeiro: ENAP 2002. 
WANDERLEY, Maria de Nazareth Baudel. "Franja periférica”, “pobres do campo”, "camponeses": dilemas da inclusão social dos pequenos agricultores familiares. In: DELGADO, G. C.; BERGAMASCO, S. M. P. P. Agricultura familiar brasileira: desafios e perspectivas de futuro. Brasília: MDA, 2017, p. 66-80.

ZIPPERER, Darci. Microcrédito produtivo orientado na gerência da Caixa Econômica Federal no território Oeste catarinense. 2015. Dissertação (Mestrado em Políticas Sociais e Dinâmicas Regionais) - Programa de Pós-Graduação em Políticas Sociais e Dinâmicas Regionais, UNOCHAPECÓ. Chapecó, 2015. 